\title{
Effect of chemical composition and alumina content on structure and properties of ceramic insulators
}

\author{
ARMAN SEDGHI ${ }^{\mathrm{a}, \mathrm{c}}$, NASTARAN RIAHI-NOORI ${ }^{\mathrm{b}, *}$, NASER HAMIDNEZHAD ${ }^{\mathrm{c}}$ and \\ MOHAMMAD REZA SALMANI \\ ${ }^{a}$ Department of Materials Engineering, Imam Khomeini International University, Qazvin, Iran \\ ${ }^{\mathrm{b}}$ Ceramic \& Polymer Group, Niroo Research Institute, Tehran, Iran \\ ${ }^{c}$ Faculty of Materials Engineering, Islamic Azad University, Saveh Branch, Iran
}

MS received 23 April 2012; revised 17 October 2012

\begin{abstract}
In the present work, six electrical porcelain compositions with different amount of alumina and silica have been prepared and fired in an industrial furnace at $1300{ }^{\circ} \mathrm{C}$. Density, porosity, bending strength and electrical strength were measured in the samples. In order to find a relationship between properties and sample microstructures, samples were analyzed by scanning electron microscope (SEM) and x-ray diffraction (XRD) techniques. The results showed that, with chemical composition of $53.5 \mathrm{wt} . \% \mathrm{SiO}_{2}$ and $37.5 \mathrm{wt} \%$ alumina, highest electrical strength of $21.97 \mathrm{kV} / \mathrm{mm}$ was achieved in fabricated electrical porcelains. Increasing amount of alumina up to $30 \mathrm{wt} . \%$ decreases quartz and cristobalite phases, but increases corundum phase 3 to 5 times. SEM observation revealed that dense particles and uniform distribution of long and thin needle shaped mullite are predominant in sample microstructures with highest electrical strength.
\end{abstract}

Keywords. Porcelain insulators; bending strength; dielectric strength; phase structure; mullite structure.

\section{Introduction}

Electrical porcelains are widely used in transportation and distribution of electricity. The main responsibility of these porcelains is insulating of electrical lines from support structure. These porcelains must have good mechanical and electrical properties and must retain these properties for more than 30 years (Ramaswamy et al 2005). In high voltage insulators, the main objective in recent decades is to increase the mechanical and electrical strength properties. These are achieved through the development of materials from hard porcelain to quartz and alumina porcelain based materials (Gobur et al 1999). In IEC672-2 standard, these porcelains are classified into five groups:

(I) Steatite porcelains (class C-220).

(II) Quartz porcelains (class C-110).

(III) Alumina porcelains (class C-120 with 30-50 wt.\% alumina and class $\mathrm{C}-130$ with more than $50 \mathrm{wt} . \%$ alumina).

(IV) Cristobalite porcelain (class C-112).

(V) High alumina porcelains (class C-780 with 80-86 wt.\% alumina and class C-786 with $86-94.5$ wt.\% alumina) (IEC 672-2 1980).

In these groups, bending strength increased from $70 \mathrm{MPa}$ in steatite porcelains to $250 \mathrm{MPa}$ in high alumina porcelains (Gorur et al 1999). In addition to high strength of this group,

\footnotetext{
*Author for correspondence (nriahi@nri.ac.ir)
}

high alumina porcelain has been used widely in fabrication of high voltage insulators because of their low electrical conductivity, stability in oxidative and corrosive environments and good resistance to aging (Holtzhausen 1992).

Silicate and alumina porcelains have highest application among electrical porcelains, but increase of glass phase in silicate porcelains lead to decrease in electrical strength in these materials. In silicate based porcelains, presence of undissolved quartz lead to initiation of non-coherent interface in structure, micro crack formation and decrease of mechanical properties (Amig and Serrano 2005). Cooling the insulator sample $\left(573{ }^{\circ} \mathrm{C}\right)$ results in quartz grain volume decrease of $2 \%$. This can produce sufficient strain to cause cracking of the glassy matrix and the quartz grains. The cracking severity is dictated by the quartz particle size and the cooling rate (Carty and Senapati 1998). On the other hand, alumina based porcelains do not have any phase transformation. They do not have any affinity for crack formation during cooling and are, therefore, usually stronger than quartz porcelains. This behaviour is related to corundum phase formation in these porcelain types (Morrell 1985; Vazquez and Mejia Velasquez 1998). By increasing alumina content in these porcelains up to $15 \%$, mechanical strength is increased to $44 \%$ and quartz to mullite ratio decreased in comparison to porcelain samples without alumina (Vazquez and Mejia Velasquez 1998). It is reported in a research work that the replacement of filler material by alumina increases the mechanical strength and, if its volume fraction is increased to $36 \%$ by weight, the bending strength of porcelain increases by $200 \%$ (Khandelwal and Cook 1970). 
Microstructure has major effect on strength and reliability of high alumina porcelains. The main factors influencing physical and mechanical properties of porcelains are grain size, amount and distribution of produced phases in the production process (Khandelwal and Cook 1970). Orlova et al found that, in alumina porcelains, optimum mechanical properties are achieved by using a corundum microstructure with less than $3 \mu \mathrm{m}$ diameter well distributed particles (Vazquez and Mejia Velasquez 1998). On the other study strength of alumina porcelains are related to acicular mullite interlocking as well as mullite amount and size (Ebrahimi et al 2000). Otherwise, the glassy phase and unresolved quartz particles are the two major parameters of porcelain material. Because of high mobility of ions, acceptable electrical performance may be achieved with decrease in the glassy phase (Vazquez and Mejia Velasquez 1998).

In this research programme, changes in the chemical composition, especially the alumina content on the mechanical and electrical properties as well as the microstructure of porcelains, have been investigated. This study is mainly focused on the development of the chemical composition of high voltage porcelains.

\section{Experimental}

The materials used in this research are: Quartz (Setabran Mine, Esfahan, Iran), Alumina (Nabaltec Company, Germany), Potassium Feldspar (Chghai Mine, Hamedan, Iran), Zenuz Kaolin (Marnd Mine, Ardebil, Iran), Abadeh Ball clay (Abadeh Mine, Shiraz, Iran) and Kerman Ball clay (Kerman Mine). The results of chemical analysis of raw materials are shown in table 1 .

The start point and reference base of this study is an electrical insulator, fabricated in Iran Insulators Company production line. This body is named TN1. Alumina content of this commercial product was increased and amount of $\mathrm{SiO}_{2}$ was decreased based on it in each sample and five samples were fabricated (table 1).

For fabrication of samples, powders were mixed by wet grinding for $6 \mathrm{~h}$ until their particle size was reduced to less than 45 microns and then filter pressed by industrial filter press. To shape samples, the mixture was extruded by Netzsch (ID-8672SELB) extruder and different diameter $(11,30$ and $50 \mathrm{~mm})$ test samples were produced. The samples were held for 4-8 $\mathrm{h}$ at ambient temperature and then dried for $2 \mathrm{~h}$ at $50{ }^{\circ} \mathrm{C}$ followed by drying at $110{ }^{\circ} \mathrm{C}$ for $4 \mathrm{~h}$ in an industrial furnace. The total firing cycle involved was $48 \mathrm{~h}$ at maximum temperature of $1300{ }^{\circ} \mathrm{C}$. Bulk density of samples was calculated according to ASTM-C37388 and shrinkage was determined by measuring diameter and length of samples in each stage. Bending strength was determined by three points bending test, as per IIC 672-2 standards, using Stavebi-B167 bending strength equipment. Electrical strength test was done in an isolated chamber with one spherical and one flat brass electrode. Chamber was filled with liquid dielectric with an electrical resistance of $10^{10}-10^{12} \Omega \cdot \mathrm{cm}$.

To identify phase structure, samples were powdered to a size of less than 75 microns and analyzed by x-ray diffractometer (BRUKER) with $\mathrm{Cu}$ target. Diffraction curves were analyzed by comparison with JCPDS cards 15-776A (mullite), 10-173 (corundum) 5-0490 (quartz) 11-695 (cristobalite).

For microstructural observation, the samples were polished mechanically and by diamond paste $(1 \mu \mathrm{m})$. Then, they were etched by $10 \mathrm{wt}$ \% HF acids for 3-4 min. Sample morphologies were studied by XL30 Phillips scanning electron microscope (SEM).

\section{Results and discussion}

The density and porosity of fabricated samples is shown in table 2 .

Based on table 2, when silica was replaced with alumina in the main composition of body insulators, the density of bodies increased. This was because of the higher density of alumina compared to that of silica. Also porosities of TN1 to TN4 decreased. This may be related to decrease of micro cracks around silica grains. As Vazquez and Mejia Velasquez (1998) have reported, by decreasing silica content in porcelain body and replacing it by alumina, micro cracks around silica particles decrease and, by using suitable sintering temperature, the highest density and the least porosity are achieved. The bending strength of TN1-TN6 bodies is plotted in figure 1 .

Table 1. Amounts of raw materials in the fabricated samples (wt.\%).

\begin{tabular}{lrrrrrr}
\hline Body no. & TN1 & TN2 & TN3 & TN4 & TN5 & TN6 \\
\hline Quartz & 25 & 20 & 15 & 10 & 5 & 0 \\
Alumina & 0 & 5 & 10 & 15 & 20 & 25 \\
Feldspar & 15 & 15 & 15 & 15 & 15 & 15 \\
Ball clay & 25 & 25 & 25 & 25 & 25 & 25 \\
Kaolin & 35 & 35 & 35 & 35 & 35 & 35 \\
\hline
\end{tabular}

Table 2. Density and porosity of samples.

\begin{tabular}{lcc}
\hline Body no. & $\begin{array}{c}\text { Average of } \\
\text { density }\left(\mathrm{kg} / \mathrm{m}^{3}\right)\end{array}$ & $\begin{array}{c}\text { Average of } \\
\text { porosity }(\%)\end{array}$ \\
\hline TN1 & 2300 & $3 \cdot 32$ \\
TN2 & 2320 & 2.73 \\
TN3 & 2360 & 1.54 \\
TN4 & 2430 & 0.09 \\
TN5 & 2520 & $0 \cdot 28$ \\
TN6 & 2570 & 1.35 \\
\hline
\end{tabular}


As observed from figure 1, there is no appreciable change in the bending strength of TN1 to TN3, but there is a significant increase in the value of bending strength for the samples TN3 to TN6. Perhaps, the compositional change has resulted in the increase in the bending strength of TN6 compared to that of TN3. Islam et al (2004) have reported that the increase in the alumina content in porcelain material increases the mullite phase which, in turn, increases the bending strength. Thus, the present finding gets good support from the reported work (Islam et al 2004) in respect of the increase of bending strength.

Electrical strength of fired samples was measured and is shown in figure 2. Based on this figure, electrical strength was increased from $18.5 \mathrm{kV} / \mathrm{mm}$ in TN1 sample to $21.9 \mathrm{kV} / \mathrm{mm}$ in TN4 sample and then decreased in TN5

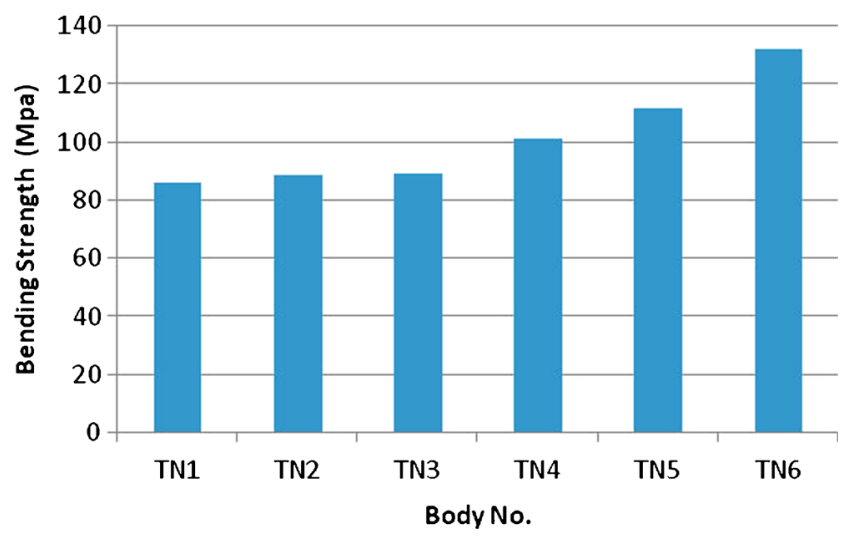

Figure 1. Bending strength variation in fired samples with different chemical composition. and TN6 samples. It can occur because of low temperature of sintering. Low temperature of sintering is unsuitable for high alumina samples and also lack of liquid phase for filling open pores may be responsible for decrease of electrical strength in high alumina samples (TN5 and TN6 samples). Capillary cracks around the unsolved quartz phase are one of the reasons for low electrical strength. In the research by Islam et al (2004), sintering temperature of high alumina porcelain bodies were optimized up to $1350{ }^{\circ} \mathrm{C}$ which is higher than the temperature of our industrial sintering furnace.

$\mathrm{XRD}$ results in figure 3 show that, by increasing alumina

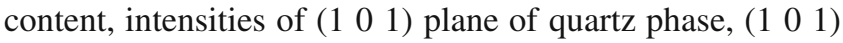
and $(200)$ planes of cristobalite phase are reduced by about $5-65 \%$, intensity of (2 30 ) and (2 20 ) planes of mullite increased by $100 \%$ and intensity of (l $\left.\begin{array}{lll}1 & 0 & 4\end{array}\right),\left(\begin{array}{lll}1 & 1 & 3\end{array}\right),\left(\begin{array}{lll}0 & 2 & 4\end{array}\right)$

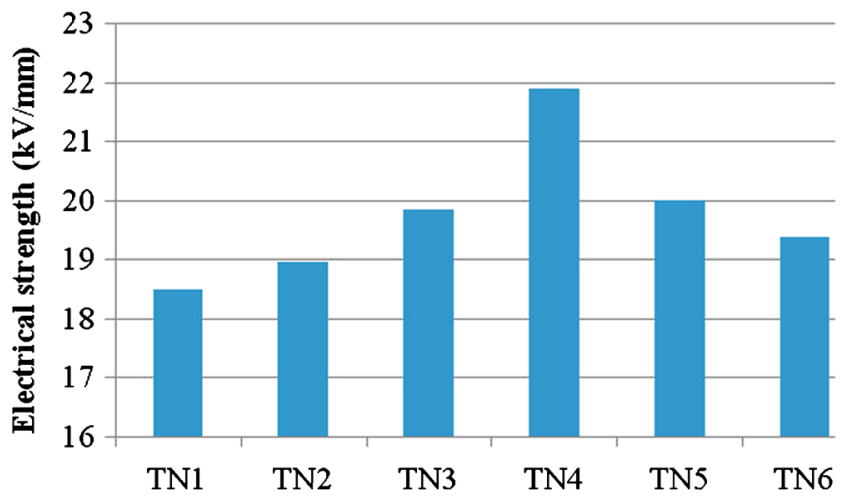

Figure 2. Electrical strength variation in fired samples with different chemical composition.

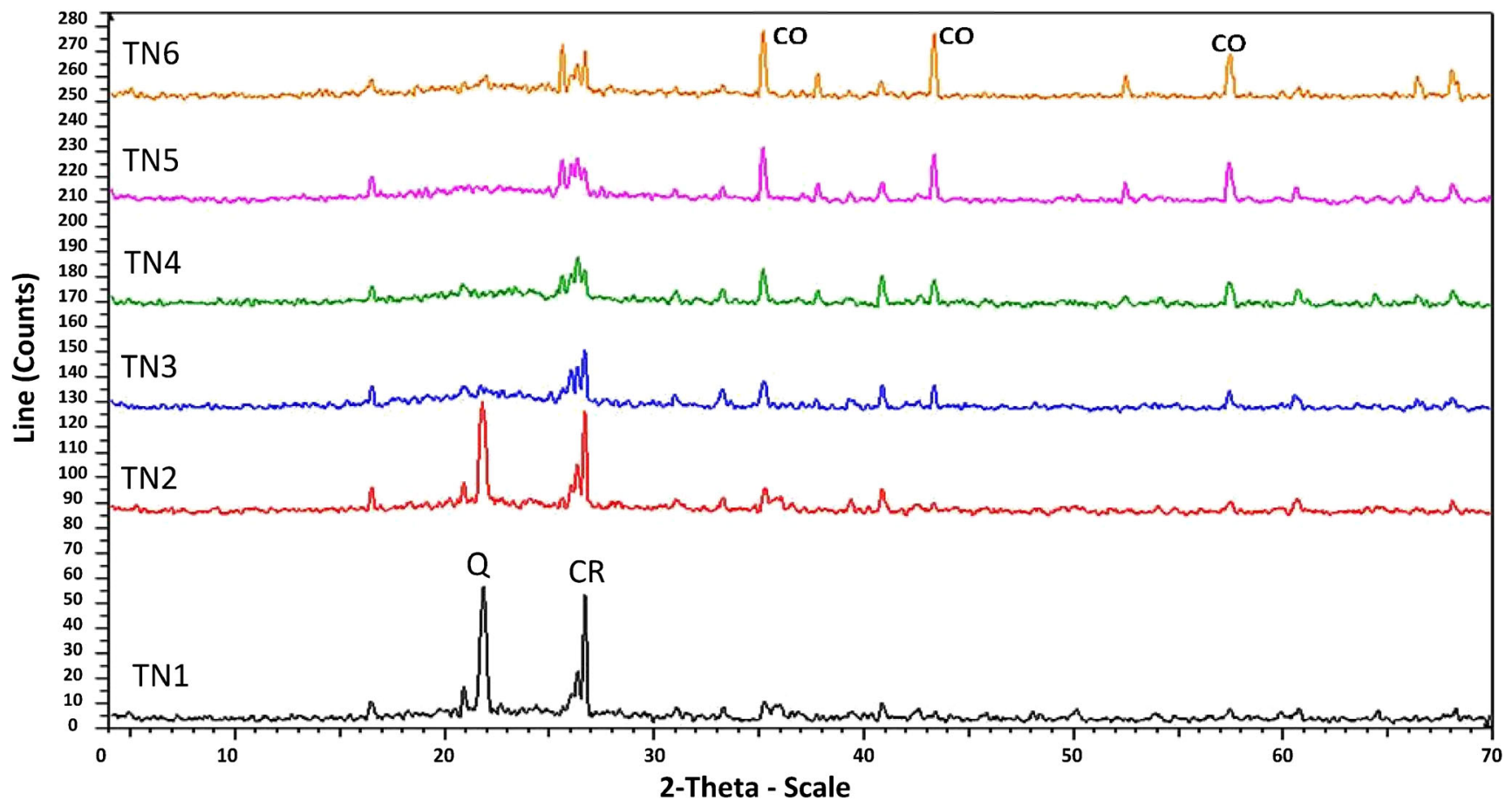

Figure 3. Comparison of $x$-ray diffraction of samples. 


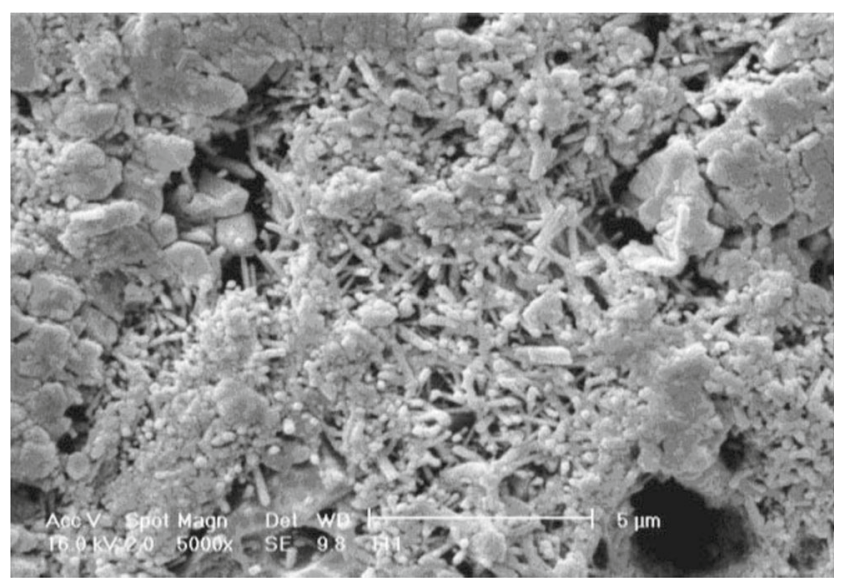

Figure 4. SEM of TN1 body etched by $10 \%$ HF for $4 \mathrm{~min}$.

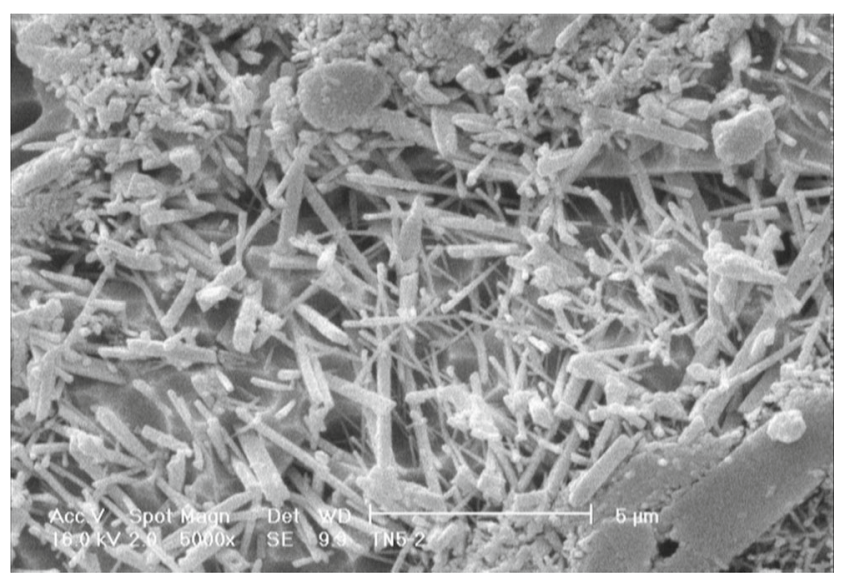

Figure 5. SEM of TN2 body etched by $10 \%$ HF for $4 \mathrm{~min}$.

and (1 1 6) planes of corundum peaks increased by about 300 to $500 \%$.

XRD results of TN1 and TN6 samples show the presence of silica and cristobalite phases (figure 3 ) leads to low electrical strength in these samples.

As per figure 3, quartz and cristobalite peak are decreased with increasing alumina content. Thus, increase of corundum and mullite phases and decrease of silica phase has resulted in increase of the bending strength from TN1 to TN6.

As explained, the electrical strength was reduced from TN4 to TN6. According to figure 3 it is understood that there was an increase in corundum phase in these samples. The increase in corundum phase concentrations requires higher firing temperature, but in the present case, insufficient firing temperature of $1300{ }^{\circ} \mathrm{C}$ would have lead to higher porosity levels and defects in these samples.

Scanning electron microscope images of TN1 to TN6 samples are shown in figures 4 to 9 . Figure 4 shows thick and small needles of mullite surrounded by unsolvable quartz particles. Ramaswamy et al (2005) have reported that low electrical and mechanical strength in porcelain body is due to small and thick needle shaped mullite and unsolved quartz in microstructure. The loss in electric strength is attributed

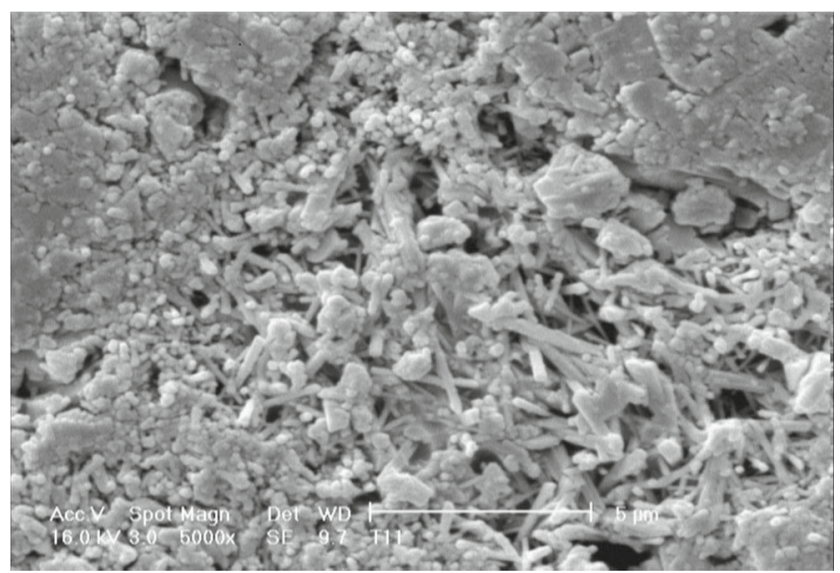

Figure 6. SEM of TN3 body etched by $10 \% \mathrm{HF}$ for $4 \mathrm{~min}$.

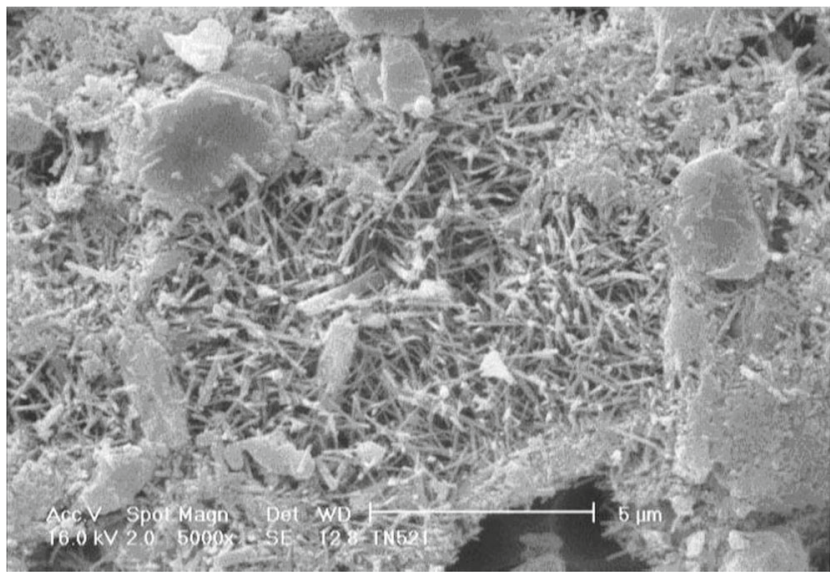

Figure 7. SEM of TN4 body etched by $10 \% \mathrm{HF}$ for $4 \mathrm{~min}$.

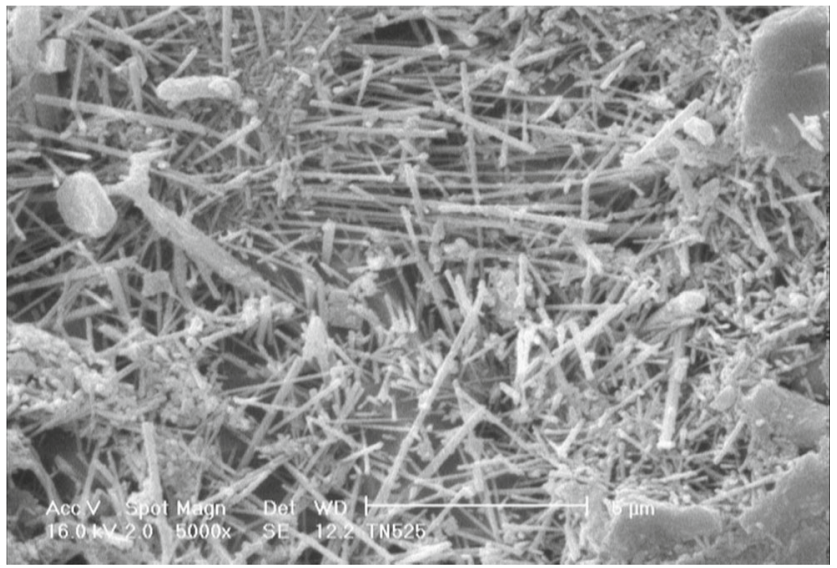

Figure 8. SEM of TN5 body etched by $10 \% \mathrm{HF}$ for $4 \mathrm{~min}$.

to the micro cracks formation adjacent to $1-5 \mathrm{~nm}$ diameter quartz particles (Ramaswamy et al 2005).

Figure 9 shows longer and thinner mullite needles in TN6 sample. Corundum phase has a compressed bulky feature. Change of mullite and corundum morphology (length and thickness) varies with increase of alumina and decrease of 


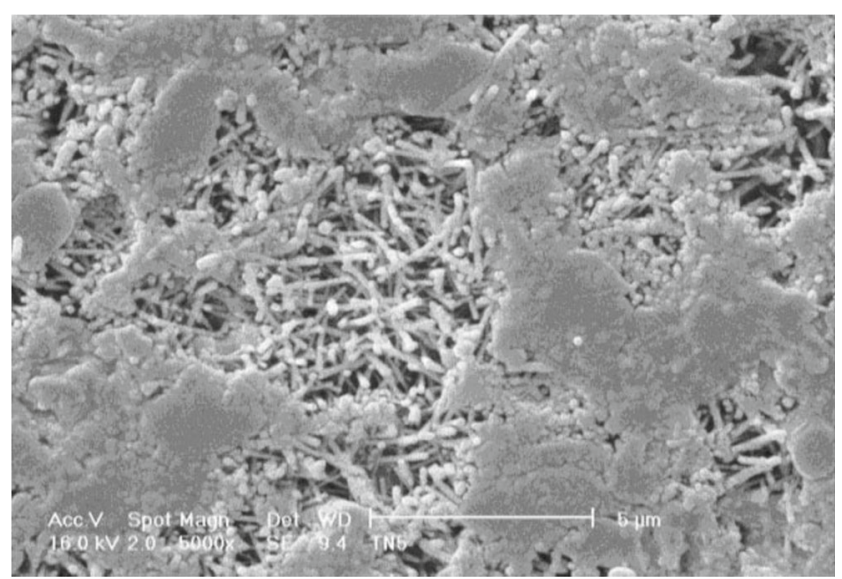

Figure 9. SEM of TN6 body etched by $10 \%$ HF for $4 \mathrm{~min}$.

silica in insulator samples. This change in mechanical and physical properties of insulators is similar to the results reported by Ramaswamy et al (2005) but some features are observed which need to be studied further.

\section{Conclusions}

In this study, different results were obtained as follows:

(I) Replacement the silica with alumina is suggested in order to high voltage porcelain insulators manufacturing.

(II) The amount of porosity decreases with increase in alumina content up to $15 \%$, but the porosity increases with further increase in alumina content to $25 \%$.

(III) Bending strength of porcelain insulator bodies increases up to $132 \mathrm{MPa}$ when alumina content is increased in suggested porcelain bodies.
(IV) The electrical strength increases to $21.3 \mathrm{kV} / \mathrm{mm}$, with increase in the alumina content up to $15 \%$, but with further increase in alumina content up to $25 \%$, the electrical strength drops down which may be attributed to the high porosity observed in these samples.

(V) The TN4 composition seems to be the best choice having good morphology of alumina with highest electrical strength.

\section{Acknowledgement}

This research was supported by Iran Insulator Company.

\section{References}

Amig J M and Serrano F J 2005 J. Eur. Ceram. Soc. 251479

Carty W M and Senapati U 1998 J. Am. Ceram. Soc. 3

Ebrahimi M E et al 2000 J. Mater. Res. 15

Gorur R S, Cherney E A and Burnham J T 1999 Outdoor insulators (Phoenix, Arizona, USA: Ravi S. Gorur, Inc.) p. 256

Holtzhausen J P 1992 High voltage insulator (USA) 125

IEC 672-2 1980 Specification for ceramic and glass insulating material, 1 edn

Islam R A, Chan Y C and Md Fakhrul Islam 2004 Mater. Sci. Eng. Bull. 106132

Khandelwal S K and Cook R L 1970 Ceram. Bull. 49

Morrell R 1985 Handbook of properties of technical and engineering ceramics Part I National Physical Laboratory, 305

Ramaswamy P, Vyatheya S and Seetharamu S 2005 Bull. Mater. Sci. 28681

Vazquez S B and Mejia Velasquez J C 1998 Alumina additions affect elastic properties of electrical porcelain Institute de Investigations Mexico 